\title{
CURSOS TÉCNICOS PÓS-MÉDIOS: \\ ANÁLISE DAS POSSÍVEIS RELAÇÕES COM O FENÔMENO DE CONTENÇÃO DA DEMANDA PELO ENSINO SUPERIOR
}

\author{
TECHNICAL POST-SECONDARY COURSES: \\ ANALYSIS OF A POSSIBLE RELATIONSHIP WITH THE PHENOMENON \\ OF RESTRICTING THE DEMAND FOR THE STATE UNIVERSITIES
}

Sonia Regina Mendes 1

Resumo Pode-se interpretar a separação entre o ensino médio e a educação profissional como um movimento que objetiva, mais uma vez, livrar a universidade pública do atendimento de contingentes cada vez maiores de alunos que concluem o ensino médio. Analisa-se, aqui, o caráter nãomanifesto das orientações para a educação profissional expressas por meio do Decreto Federal 2.208/97, a partir do levantamento dos percursos escolares dos alunos que freqüentaram os cursos técnicos pós-médios nas escolas técnicas federais e no Serviço Nacional de Aprendizagem Industrial (SENAI) do Rio de Janeiro, nos anos de 1999 e 2000. Este documento indica, mais uma vez, uma tentativa do governo em conter o número de matrículas para o ensino superior público. A realidade dos alunos dos cursos técnicos pós-médios na cidade do Rio de Janeiro, ministrados de forma contínua em escolas técnicas federais e no SENAI nos anos finais do século XX, contribui para refletirmos sobre as intenções e possíveis repercussões da separação do ensino médio da educação profissional de nível técnico para boa parte dos alunos egressos do ensino médio.

Palavras-chave educação profissional; cursos técnicos pós-médios; política educacional.
Abstract It is possible to view the separation between secondary schooling and professional education as a movement that, once more, aims at keeping away from the State Universities the increasingly greater number of students that complete secondary education. With the help of a survey of the school trajectory of students that attended technical post-secondary courses in the Federal technical schools and in the National Service of Industrial Learning (SENAI) of Rio de Janeiro in the years 1999/2000, we analyse here the non-manifest character of the guidelines for professional education expressed in the Federal Law 2208/97. Once again, this document reflects the Government's attempt to reduce the number of places in State Universities. The experience of the students attending the technical post-secondary courses that were being ministered in the federal technical schools and at the SENAI in the city of Rio de Janeiro uninterruptedly during the late years of the 20th century can help us to understand the intentions behind the separation of secondary education from technical-level professional education and the possible repercussions of this separation for a large number of students now leaving secondary school.

Key words professional education; technical post-secondary courses; educational policies. 


\section{Introdução}

As reformas do ensino médio e da educação profissional através da Lei 9394/ 96 e do Decreto Federal 2.208/97 trazem como grande inovação, entre outros aspectos, a separação do ensino técnico-profissional do ensino médio em geral. Pela atual legislação de ensino, a educação profissional está organizada em capítulo à parte da educação básica e do ensino superior. Definiu-se, no artigo 39 da nova Lei de Diretrizes e Bases da Educação Nacional (LDB), que o aluno matriculado ou egresso do ensino fundamental, médio e superior, bem como o trabalhador, contarão com a possibilidade de acesso à educação profissional. No artigo 40, estabelece-se que a educação profissional será desenvolvida em articulação com o ensino regular, este compreendendo os níveis fundamental, médio e superior. Dessa forma, a educação profissional é tratada como complementar à educação de caráter geral.

Segundo o texto do Decreto Federal 2.208/97, a educação profissional poderá ser realizada em escolas de ensino regular, em instituições especializadas ou nos ambientes de trabalho. Em especial, o preparo de profissionais técnicos poderá ocorrer no nível do ensino médio de forma paralela ou após atendida a formação geral do educando. Neste decreto, definiu-se que o ensino técnico terá uma organização curricular independente da utilizada para o ensino médio.

Outra inovação no ensino técnico é a possibilidade de o curso ser feito em partes, em módulos. Após cada fase cursada, o aluno receberá um certificado que comprovará sua qualificação para atuar imediatamente no mercado de trabalho.

As mudanças definem também um novo papel para as escolas técnicas federais, que terão como prioridade a formação de profissionais através de cursos básicos, de cursos de formação de técnicos e de formação de tecnólogos. Um dos fortes argumentos do governo para empreender todas as mudanças na educação profissional é que as escolas técnicas, por meio do seu modelo integrado de educação profissional, acabaram, na prática, por tornar-se, em sua essência, preparatórias de bons candidatos para o vestibular, sendo, inclusive, disputadas pela elite. Além disso, a rede de escolas técnicas, pelo modo como organiza o ensino técnico, atende a uma minoria da população escolar.

Quando se consideram as novas regras para a formação profissional, no entanto, se observa que as mesmas se apóiam numa solução já em prática no país: a organização de cursos técnicos estritos, destinados a oferecer a parte de formação profissional de um curso técnico para quem já concluiu o curso de ensino médio. Esses cursos foram ministrados de forma contínua nos últimos dez anos em algumas escolas técnicas federais e no SENAI. Com o Decreto Federal 2.208/97, em que se concebe uma organização independen- 
te para o ensino técnico, enaltece-se o que era oferecido a egressos do ensino médio em termos de formação profissional do nível técnico.

Durante sua existência, os cursos técnicos, estritos em cada uma daquelas instituições, passaram por toda uma série de reajustamentos; entre outros, revisões curriculares, modificações no processo de avaliação dos alunos, e alterações no processo de seleção e admissão do alunado.

Resgatar um pouco dessa história, por intermédio das características dos seus alunos, e descobrir com que finalidade os alunos buscavam um curso técnico após o término do ensino do ensino médio constituem a preocupação central deste trabalho.

\section{Cursos técnicos pós-médios: entre a inovação e a "contenção" ao ensino superior}

Desde o final da década de 70, os egressos do então curso de 20 grau, caso desejassem, poderiam concluir sua formação técnica em escolas que ministrassem cursos específicos. As instituições que ofereciam tais cursos, de modo geral, passaram a denominá-los de curso técnico especial ou pós-secundário. No início dos anos 80, os cursos técnicos pós-secundários começam a ser oferecidos, paulatinamente, pelas escolas técnicas federais e pelo SENAI. Mesmo assim, ao final dessa década, as experiências em quase todas essas instituições de ensino ainda eram bastante escassas.

No âmbito das instituições privadas, é importante destacar que, de um modo geral, tais instituições manifestaram pouquíssimo interesse em oferecer tal modalidade de curso. Para elas, os alunos preferiam realizar cursos de 2 o grau que já concediam habilitação de técnico de nível médio. Portanto, a modalidade preferencialmente adotada por todas as instituições, tanto públicas como privadas, foi a organização desses últimos.

A própria concepção de ensino técnico de nível médio pressupunha um curso que simultaneamente profissionalizasse o aluno e o preparasse para o prosseguimento de estudos posteriores. No âmbito do governo federal, os cursos técnicos foram oferecidos pelas escolas técnicas federais e pelos centros de educação tecnológica, que sempre procuraram manter um ensino de qualidade.

Na segunda metade da década de 90, pesadas críticas são dirigidas ao ensino técnico propiciado por essas instituições. Tem início o processo de separação do ensino técnico do ensino médio. Segundo as análises do MEC, a desvinculação entre os dois traria algumas vantagens: o aluno teria mais flexibilidade na definição do seu itinerário de educação profissional, não ficando preso à rigidez de uma habilitação profissional no ensino médio de três ou quatro anos. As instituições de ensino, por sua vez, com mais flexi- 
bilidade também, poderiam permanentemente rever seus currículos em função das demandas do mercado de trabalho.

Um outro fator ressaltado foi a consideração de que o alto custo do ensino técnico não justificaria uma escola que tivesse como clientela padrão a classe média, essa mesma classe média que procura na escola pública de qualidade a adequada preparação ao enfrentamento dos exames vestibulares para os cursos superiores e para a inserção no mercado de trabalho. Segundo o discurso oficial, o ensino técnico oferecido pelo sistema federal de ensino não atingia os trabalhadores e se revestia mais de características propedêuticas do que profissionalizantes, ou seja, estava voltado para a preparação dos alunos para os processos seletivos do ensino superior.

Tais análises parecem desconsiderar que, muito provavelmente, um ensino técnico de menor custo pode vir de contramão às novas exigências da reestruturação produtiva. É cada vez mais recorrente a afirmação de que uma sociedade industrializada necessita de uma força de trabalho altamente qualificada com habilidade prática e capacidade de raciocínio abstrato.

Cláudio de Moura Castro (1997), no célebre documento sobre a análise do ensino secundário, $O$ secundário esquecido ou um desvão do ensino?, definiu a separação entre as partes acadêmica e profissional como solução para eliminar a procura pelas escolas técnicas federais como meras encaminhadoras de seus egressos ao vestibular: “(...) na verdade, esta solução corre próximo do que as escolas técnicas do SENAI estão chamando de técnico especial. A vantagem desta solução é que, com uma cirurgia menor, elimina-se totalmente a presença no técnico de alunos cuja meta é o vestibular" (Castro, 1993, p. 8).

Com a separação entre educação geral e formação profissional, os cursos técnicos seriam efetivamente procurados por aqueles que estivessem basicamente interessados numa carreira técnica. E mais, acrescenta o autor, com a separação entre as partes profissional e acadêmica, as escolas técnicas federais poderiam atender a um maior número de alunos. Estes foram os argumentos fundamentais para a edição do Decreto Federal 2.208/97, reformulando a educação profissional.

Através desse entendimento, as escolas técnicas deixam de lado o que foi considerado desperdício e atentam para o seu objetivo de formar profissionais que efetivamente destinam-se ao mercado de trabalho.

Entretanto, um outro fator parece também concorrer para as mudanças concernentes à educação profissional: a velocidade da expansão do ensino médio na década de 90 no Brasil. Maria Helena Guimarães de Castro (1998), presidente do Instituto Nacional de Estudos e Pesquisas Educacionais (INEP), ao apresentar os principais resultados obtidos nos censos educacionais realizados, destaca que, no período de 1990 a 1998, o número de matrículas nesse nível de ensino aumentou de 3,5 milhões para aproximadamente 6,9 milhões. Segundo ela, pode-se caracterizar a década de 90 como a da democra- 
tização do ensino médio. O número de concluintes também duplicou, passando de 658 mil, em 1990, para 1,3 milhão, em 1997. Para a autora, esse aumento certamente indica uma forte pressão por vagas no ensino superior e também em cursos profissionalizantes pós-médios.

Em sua análise, Helena Castro afirma que o ensino médio pode se expandir ainda mais, principalmente quando se considera que menos de $30 \%$ da população entre 15 e 17 anos encontra-se matriculada. Em relação aos índices de matrícula, o Brasil se situa bem abaixo de países desenvolvidos como França e Inglaterra, onde mais de $80 \%$ da população nessa faixa etária freqüenta escola secundária. Grande será o desafio do governo para assegurar a expansão de vagas no ensino médio e promover, simultaneamente, a melhoria da qualidade do ensino.

O resultado expressivo da década de 90 , do ponto de vista da expansão das vagas, não foi acompanhado pelos indicadores de eficiência do sistema: houve um aumento da taxa de repetência, que de $25 \%$, em 1981, passou para 36\%, em 1998, e um declínio da taxa de promoção, que de $67 \%$, em 1981, passou para $60 \%$ naquele mesmo período, em 98 . O atendimento a uma clientela mais heterogênea explica o fato. A distorção série/idade demonstra que $50 \%$ dos alunos concluem o ensino médio fora da idade esperada de $17 / 18$ anos, dos quais $25 \%$ têm mais de 21 anos.

Ao analisarmos os dados do Exame Nacional do Ensino Médio (Enem) aplicado em 115.575 alunos em 1998, pode-se verificar a baixa qualidade do ensino médio. Os estudantes que voluntariamente realizaram o exame obtiveram nota média quatro na prova de conhecimentos gerais, considerada insuficiente pelos critérios do INEP. No questionário socioeconômico, 92,9\% dos alunos desejavam continuar seus estudos, ingressando no curso superior.

Ainda na visão da autora, o ensino médio atual é menos elitizado do que na década de 80; o número de jovens que concluem as oito séries do ensino fundamental e chegam ao ensino médio é cada vez maior. Em 1998, a rede pública estadual já respondia por $72,5 \%$ das matrículas do ensino médio, o que leva a supor que a demanda por novas vagas continuará a ocorrer majoritariamente no âmbito do sistema estadual.

A implementação da reforma da educação profissional e do ensino médio pode, sem dúvida, ter sido calcada nesses vários fatores. $\mathrm{O}$ crescimento de vagas oferecidas no vestibular tem sido lento em relação ao aumento do número de concluintes do ensino médio e, com a rápida melhora do desempenho do ensino médio, a procura por vagas tende a aumentar. Nesse quadro de expansão do ensino médio, tornou-se cada vez mais necessária a criação de cursos técnicos pós-médios. A alternativa é considerada pelo governo como vantajosa para grande parte dos egressos de ensino médio que, embora revelem expectativa de continuidade de estudos, não serão absorvidos pelo ensino superior. 
Dessa forma, mantém-se para os egressos do ensino médio a dicotomia concentrada nesse nível de ensino: para uns, a oferta de cursos técnicos pósmédios, para outros, o ingresso na universidade. Teriam os alunos egressos do ensino médio, diante das novas orientações para a educação básica e profissional, que enfrentar uma nova "política de contenção"2 de matrículas no ensino superior?

Através de novos entendimentos sobre a política de ensino médio e educação profissional, podemos estar diante de novas formas contenedoras em relação ao ensino superior público e gratuito. Os recentes encaminhamentos para o ensino médio e a educação profissional podem ser interpretados como um novo movimento para, mais uma vez, livrar a universidade pública do atendimento de contigentes cada vez maiores de alunos que concluem o ensino médio.

Dessa vez, a alternativa encontrada estaria no processo de separação entre o ensino técnico e o ensino médio: aquele curso poderia ser realizado em concomitância ou de forma seqüencial a este. Ao que se sabe, se o ensino médio já é realizado pela maioria de alunos-trabalhadores em cursos noturnos, podemos vislumbrar que esses alunos só poderão realizar uma formação profissional de nível técnico após o ensino médio, ou melhor, em seqüência ao ensino médio. Com efeito, um contingente de alunos sem condições objetivas de enfrentar o vestibular para as universidades públicas estaria destinado à educação profissional de nível técnico. O que resta desvelar é quem constituiria esse grupo de alunos, quais suas características definidoras e quais seus percursos escolares e profissionais.

Com a separação entre o ensino médio e a educação profissional, uma parcela de possíveis candidatos aos exames vestibulares das universidades públicas se direcionará à educação profissional de nível técnico. Para muitos, esta será a única alternativa para obter uma formação profissional, uma vez que percebem que são poucas as chances de ingresso no ensino superior público, principalmente por terem recebido um ensino médio de qualidade questionável.

Solução elitista ou contenedora, afinal o que se pode afirmar sobre o ensino técnico desvinculado do ensino médio?

\section{Os alunos dos cursos técnicos pós-médios: o que seus percursos escolares podem revelar?}

Muito se tem afirmado sobre as aspirações dos alunos egressos do ensino médio, concentrados ora no ingresso no ensino superior, ora na inserção imediata no mercado de trabalho. Mediante essas análises, o MEC vem traçando as políticas para o ensino médio e a formação profissional. Ainda se- 
gundo o Conselho Nacional de Educação (CNE), os cursos técnicos pós-médios são considerados experiências exitosas que atendem alunos exclusivamente preocupados com a formação profissional.

Diante de tais considerações, foi preciso conhecer as expectativas concretas dos alunos dos cursos técnicos pós-médios, principalmente analisando os percursos escolares traçados após a conclusão do ensino médio.

Para tal, foi elaborado um questionário semi-aberto, aplicado em 331 alunos dos cursos técnicos pós-médios matriculados na Escola Técnica Federal de Química (Curso de Química), no Centro de Educação Tecnológica Celso Suckow da Fonseca (Curso de Segurança do Trabalho, Telecomunicações e Saneamento Ambiental) e em algumas unidades do Serviço Nacional de Aprendizagem Industrial (SENAI) do Rio de Janeiro (Cursos de Programação Visual, Instalações e Edificações, Solda, Mecânica, Eletrotécnica e Instrumentação) durante os anos de 1999 e 2000.

$\mathrm{O}$ instrumento foi feito com a intenção de identificar algumas características centrais desse alunado, tais como sexo, faixa etária, tipo de escola cursada, tipo de curso realizado no ensino médio, lapso de tempo entre o término do ensino médio e início do curso técnico, número de tentativas realizadas para ingresso no vestibular.

Dessa forma, foi possível identificar as características comuns dos alunos que procuravam um curso de nível técnico após o ensino médio. O que eles esperavam? Queriam ainda continuar seus estudos no ensino superior? Desejavam realizar tão-somente um curso de formação profissional de nível técnico? Pensavam em melhorar sua posição no mercado de trabalho? Que fatores puderam interferir na realização das suas expectativas?

Dentre os 331 respondentes do questionário aplicado, houve predominância do sexo masculino $(78,2 \%)$. Na turma do curso técnico pós-médio de Mecânica do SENAI, não havia mulheres. Os cursos de Eletrotécnica, Instrumentação e Instalações e Edificações registram a presença de, pelo menos, um representante do sexo feminino. Dos 12 alunos do curso de Programação Visual do SENAI, quatro eram mulheres, ao passo que nos cursos do CEFET a proporção era de uma mulher para cinco homens. Entre os cursos com maior presença feminina, o de Química da ETFQ contava com cerca de $62 \%$ de mulheres. Contudo, o predomínio de alunos cursando habilitações da área industrial nos cursos técnicos pós-médios era do sexo masculino (Tabela 1).

Precisamente $54,7 \%$ dos alunos cursaram o ensino médio exclusivamente em escolas públicas, 35,6\% em escolas particulares e 9,7\% fizeram parte do curso em escolas públicas e parte em escolas particulares (Tabela 2).

Quase metade dos alunos dos cursos técnicos pós-médios concentra-se na faixa etária de 18 a 22 anos (cerca de 45,6\%). A maioria dos alunos, 53,8\%, tinha mais de 23 anos, dos quais $28,4 \%$ mais de 27 anos (Tabela 3). 
Tabela 1

Distribuição do número de alunos dos cursos técnicos pós-médios segundo a instituição, a especialidade e o sexo

\begin{tabular}{|c|c|c|c|c|c|c|c|c|c|c|c|c|}
\hline \multirow[t]{2}{*}{ Sexo } & \multicolumn{3}{|c|}{ CEFET } & \multirow{2}{*}{$\begin{array}{c}\text { ETFQ } \\
\text { Química }\end{array}$} & \multicolumn{6}{|c|}{ SENAI } & \multirow[t]{2}{*}{ Total } & \multirow[t]{2}{*}{$\%$} \\
\hline & $\begin{array}{l}\text { Sanea- } \\
\text { mento }\end{array}$ & $\begin{array}{l}\text { Seg.do } \\
\text { Trabalho }\end{array}$ & $\begin{array}{l}\text { Teleco- } \\
\text { munic. }\end{array}$ & & $\begin{array}{l}\text { Instru- } \\
\text { ment. }\end{array}$ & $\begin{array}{l}\text { Instal. } \\
\text { e Edific. }\end{array}$ & Solda & $\begin{array}{l}\text { Progr. } \\
\text { Visual }\end{array}$ & $\begin{array}{l}\text { Eletro- } \\
\text { técnica }\end{array}$ & Mecânica & & \\
\hline Feminino & 4 & 7 & 22 & 30 & 1 & 1 & 2 & 4 & 1 & - & 72 & 21,7 \\
\hline Masculino & 19 & 35 & 107 & 18 & 10 & 14 & 11 & 8 & 24 & 13 & 259 & 78,3 \\
\hline Total & 23 & 42 & 129 & 48 & 11 & 15 & 13 & 12 & 25 & 13 & 331 & 100 \\
\hline
\end{tabular}

\section{Tabela 2}

Distribuição do número de alunos dos cursos técnicos pós-médios segundo a instituição, a especialidade e a origem escolar

\begin{tabular}{|c|c|c|c|c|c|c|c|c|c|c|c|c|}
\hline \multirow[t]{2}{*}{ Origem escolar } & \multicolumn{3}{|c|}{ CEFET } & \multirow{2}{*}{$\begin{array}{c}\text { ETFQ } \\
\text { Química }\end{array}$} & \multicolumn{6}{|c|}{ SENAI } & \multirow[t]{2}{*}{ Total } & \multirow[t]{2}{*}{$\%$} \\
\hline & $\begin{array}{l}\text { Sanea- } \\
\text { mento }\end{array}$ & $\begin{array}{l}\text { Seg. do } \\
\text { Trabalho }\end{array}$ & $\begin{array}{l}\text { Teleco- } \\
\text { munic. }\end{array}$ & & $\begin{array}{l}\text { Instru- } \\
\text { ment. }\end{array}$ & $\begin{array}{l}\text { Instal. } \\
\text { e Edific. }\end{array}$ & Solda & $\begin{array}{l}\text { Progr. } \\
\text { Visual }\end{array}$ & $\begin{array}{l}\text { Eletro- } \\
\text { técnica }\end{array}$ & $\begin{array}{c}\text { Mecâ- } \\
\text { nica }\end{array}$ & & \\
\hline Pública & 16 & 23 & 60 & 37 & 3 & 8 & 8 & 4 & 13 & 9 & 181 & 54,7 \\
\hline Particular & 4 & 14 & 54 & 11 & 6 & 5 & 5 & 7 & 10 & 2 & 118 & 35,6 \\
\hline Pública/Particular & 3 & 5 & 15 & - & 2 & 2 & - & 1 & 2 & 2 & 32 & 9,7 \\
\hline Total & 23 & 42 & 129 & 48 & 11 & 15 & 13 & 12 & 25 & 13 & 331 & 100 \\
\hline
\end{tabular}

Tabela 3

Distribuição do número de alunos dos cursos técnicos pós-médios segundo a instituição, a especialidade $\mathrm{e}$ a idade

\begin{tabular}{|c|c|c|c|c|c|c|c|c|c|c|c|c|}
\hline \multirow[t]{2}{*}{ Idade } & \multicolumn{3}{|c|}{ CEFET } & \multirow{2}{*}{$\begin{array}{c}\text { ETFQ } \\
\text { Química }\end{array}$} & \multicolumn{6}{|c|}{ SENAI } & \multirow[t]{2}{*}{ Total } & \multirow[t]{2}{*}{$\%$} \\
\hline & $\begin{array}{l}\text { Sanea- } \\
\text { mento }\end{array}$ & $\begin{array}{l}\text { Seg.do } \\
\text { Trabalho }\end{array}$ & $\begin{array}{l}\text { Teleco- } \\
\text { munic. }\end{array}$ & & $\begin{array}{l}\text { Instru- } \\
\text { ment. }\end{array}$ & $\begin{array}{l}\text { Instal. } \\
\text { e Edific. }\end{array}$ & Solda & $\begin{array}{l}\text { Progr. } \\
\text { Visual }\end{array}$ & $\begin{array}{l}\text { Eletro- } \\
\text { técnica }\end{array}$ & $\begin{array}{c}\text { Mecâ- } \\
\text { nica }\end{array}$ & & \\
\hline Menos de 18 anos & - & - & - & 1 & - & - & - & - & 1 & - & 2 & 0,6 \\
\hline $18-22$ anos & 5 & 13 & 67 & 40 & 4 & 5 & 3 & 1 & 11 & 2 & 151 & 45,6 \\
\hline $23-27$ anos & 3 & 15 & 32 & 6 & 4 & 4 & 4 & 5 & 6 & 5 & 84 & 25,4 \\
\hline $28-33$ anos & 2 & 5 & 23 & - & 3 & 1 & 3 & 6 & 5 & 6 & 54 & 16,3 \\
\hline $34-38$ anos & 5 & 4 & 4 & 1 & 0 & 1 & 2 & - & - & - & 17 & 5,1 \\
\hline Mais de 38 anos & 8 & 5 & 3 & - & - & 4 & 1 & - & 2 & - & 23 & 7,0 \\
\hline Total & 23 & 42 & 129 & 48 & 11 & 15 & 13 & 12 & 25 & 13 & 331 & 100 \\
\hline
\end{tabular}


Naquela ocasião, a presença mais intensa de jovens na faixa etária de 18 a 22 anos ocorria nos cursos de Química da ETFQ (85,4\%), de Eletrônica do SENAI (56\%) e de Telecomunicações do CEFET (51,9\%). O primeiro apresenta a maior taxa certamente devido ao convênio existente com a Secretaria de Educação do Estado, que destinava um percentual de vagas aos alunos selecionados do ensino médio das escolas públicas estaduais.

A concentração de alunos de maior faixa etária na maioria dos cursos técnicos pós-médios pode indicar que a procura dos cursos não ocorria imediatamente após a conclusão do curso de ensino médio. O que reitera essa análise é o fato de boa parte dos alunos, cerca de $61 \%$, ter ingressado no curso técnico pós-médio depois de, pelo menos, três anos de conclusão do ensino médio. A maioria havia concluído o curso antes de 1993, ou seja, do término do ensino médio à realização do curso técnico houve um intervalo de mais de cinco anos para 43,5\% dos alunos (Tabela 4).

A maior parte dos alunos, $68 \%$, havia cursado um 2 o grau comum, ou seja, de formação geral; entre eles, cerca de $4,2 \%$ provinham de cursos supletivos. Tais alunos, dos cursos de 2 o grau de formação geral, não deixaram de assinalar em seus depoimentos as grandes dificuldades enfrentadas para compatibilizar trabalho e curso de 2 o grau noturno (Tabela 5).

Mais intensamente, não deixaram de criticar os cursos freqüentados. De modo amplo, estes foram considerados deficitários, com currículos empobrecidos e defasados, que não puderam ajudá-los a prosseguir seus estudos no ensino superior (Tabela 6).

A identificação de algumas características gerais dos estudantes que realizam um curso técnico pós-médio não deixa de suscitar uma série de indagações, em especial a respeito dos percursos escolares dos que estariam prestes a ingressar no ensino superior.

Tabela 4

Distribuição do número de alunos dos cursos técnicos pós-médios segundo a instituição, a especialidade e os anos de conclusão do curso de 2 o grau

\begin{tabular}{|c|c|c|c|c|c|c|c|c|c|c|c|c|}
\hline \multirow{2}{*}{$\begin{array}{l}\text { Ano de conclusão } \\
\text { do } 2 \text { o grau }\end{array}$} & \multirow[b]{2}{*}{$\begin{array}{l}\text { Sanea- } \\
\text { mento }\end{array}$} & \multirow{2}{*}{$\begin{array}{l}\text { CEFET } \\
\text { Seg. do } \\
\text { Trabalho }\end{array}$} & \multirow[b]{2}{*}{$\begin{array}{l}\text { Teleco- } \\
\text { munic. }\end{array}$} & \multirow{2}{*}{$\begin{array}{c}\text { ETFQ } \\
\text { Química }\end{array}$} & \multirow[b]{2}{*}{$\begin{array}{l}\text { Instru- } \\
\text { ment. }\end{array}$} & \multirow[b]{2}{*}{$\begin{array}{l}\text { Instal. } \\
\text { e Edific. }\end{array}$} & \multicolumn{2}{|c|}{ SENAI } & \multirow[b]{2}{*}{$\begin{array}{l}\text { Eletro- } \\
\text { técnica }\end{array}$} & \multirow[b]{2}{*}{$\begin{array}{l}\text { Mecâ- } \\
\text { nica }\end{array}$} & \multirow[t]{2}{*}{ Total } & \multirow[t]{2}{*}{$\%$} \\
\hline & & & & & & & Solda & $\begin{array}{l}\text { Progr. } \\
\text { Visual }\end{array}$ & & & & \\
\hline 1997 & - & - & - & 12 & - & 1 & - & - & 2 & - & 20 & 4,5 \\
\hline 1996 & 2 & 4 & 20 & 13 & 1 & 2 & - & 1 & 4 & 2 & 44 & 14,8 \\
\hline 1995 & 1 & 9 & 33 & 10 & 3 & 4 & 1 & - & 3 & 1 & 65 & 19,6 \\
\hline 1994 & 2 & 6 & 14 & 2 & 3 & - & 2 & - & 4 & 1 & 34 & 10,3 \\
\hline 1993 & 1 & 2 & 9 & 5 & - & 1 & 3 & 2 & - & 1 & 24 & 7,3 \\
\hline Antes de 1993 & 17 & 21 & 53 & 6 & 4 & 7 & 7 & 9 & 12 & 8 & 144 & 43,5 \\
\hline Total & 23 & 42 & 129 & 48 & 11 & 15 & 13 & 12 & 25 & 13 & 331 & 100 \\
\hline
\end{tabular}


Tabela 5

Distribuição do número de alunos dos cursos técnicos pós-médios segundo a instituição, a especialidade e o tipo de curso de 2 o grau realizado

\begin{tabular}{|c|c|c|c|c|c|c|c|c|c|c|c|c|}
\hline \multirow{2}{*}{$\begin{array}{l}\text { Tipo de curso } \\
\text { de } 2 \text { o grau }\end{array}$} & \multicolumn{3}{|c|}{ CEFET } & \multirow{2}{*}{$\begin{array}{c}\text { ETFQ } \\
\text { Química }\end{array}$} & \multirow[b]{2}{*}{$\begin{array}{l}\text { Instru- } \\
\text { ment. }\end{array}$} & \multirow[b]{2}{*}{$\begin{array}{l}\text { Instal. } \\
\text { e Edific. }\end{array}$} & \multicolumn{2}{|c|}{ SENAI } & \multirow[b]{2}{*}{$\begin{array}{l}\text { Eletro- } \\
\text { técnica }\end{array}$} & \multirow[b]{2}{*}{$\begin{array}{c}\text { Mecâ- } \\
\text { nica }\end{array}$} & \multirow[t]{2}{*}{ Total } & \multirow[t]{2}{*}{$\%$} \\
\hline & $\begin{array}{l}\text { Sanea- } \\
\text { mento }\end{array}$ & $\begin{array}{l}\text { Seg. do } \\
\text { Trabalho }\end{array}$ & $\begin{array}{l}\text { Teleco- } \\
\text { munic. }\end{array}$ & & & & Solda & $\begin{array}{l}\text { Progr. } \\
\text { Visual }\end{array}$ & & & & \\
\hline Comum & 14 & 28 & 85 & 41 & 2 & 7 & 3 & 7 & 17 & 7 & 211 & 63,8 \\
\hline Técnico & 3 & 8 & 32 & 4 & 5 & 4 & 3 & 2 & 3 & 2 & 65 & 19,6 \\
\hline Profissionalizante & 5 & 3 & 9 & 3 & 4 & 2 & 5 & 2 & 4 & 3 & 41 & 12,4 \\
\hline Supletivo & 1 & 3 & 3 & - & - & 2 & 2 & 1 & 1 & 1 & 14 & 4,2 \\
\hline Total & 23 & 42 & 129 & 48 & 11 & 15 & 13 & 12 & 25 & 13 & 331 & 100 \\
\hline
\end{tabular}

Tabela 6

Distribuição do número de alunos dos cursos técnicos pós-médios segundo a instituição, a especialidade e a avaliação do curso de 2 o grau

\begin{tabular}{|c|c|c|c|c|c|c|c|c|c|c|c|c|}
\hline \multirow{2}{*}{$\begin{array}{l}\text { Avaliação } \\
\text { do } 2 \text { o grau }\end{array}$} & \multirow[b]{2}{*}{$\begin{array}{l}\text { Sanea- } \\
\text { mento }\end{array}$} & \multirow{2}{*}{$\begin{array}{l}\text { CEFET } \\
\text { Seg. do } \\
\text { Trabalho }\end{array}$} & \multirow[b]{2}{*}{$\begin{array}{l}\text { Teleco- } \\
\text { munic. }\end{array}$} & \multirow{2}{*}{$\begin{array}{c}\text { ETFQ } \\
\text { Química }\end{array}$} & \multirow[b]{2}{*}{$\begin{array}{l}\text { Instru- } \\
\text { ment. }\end{array}$} & \multirow[b]{2}{*}{$\begin{array}{l}\text { Instal. } \\
\text { e Edific. }\end{array}$} & \multicolumn{2}{|c|}{ SENAI } & \multirow[b]{2}{*}{$\begin{array}{l}\text { Eletro- } \\
\text { técnica }\end{array}$} & \multirow[b]{2}{*}{$\begin{array}{l}\text { Mecâ- } \\
\text { nica }\end{array}$} & \multirow[t]{2}{*}{ Total } & \multirow[t]{2}{*}{$\%$} \\
\hline & & & & & & & Solda & $\begin{array}{l}\text { Progr. } \\
\text { Visual }\end{array}$ & & & & \\
\hline \multicolumn{13}{|c|}{ Escola pública } \\
\hline Ótimo & 2 & 3 & 6 & 1 & - & - & 1 & - & 1 & - & 14 & 7,7 \\
\hline Bom & 6 & 8 & 24 & 14 & 1 & 1 & 3 & 1 & 5 & 4 & 67 & 37,0 \\
\hline Regular & 6 & 8 & 17 & 14 & 2 & 5 & 3 & 3 & 3 & 4 & 65 & 35,9 \\
\hline Ruim & 2 & 3 & 12 & 6 & - & 2 & 1 & - & 3 & 1 & 30 & 16,6 \\
\hline Péssimo & - & 1 & 1 & 2 & - & - & - & - & 1 & - & 5 & 2,8 \\
\hline Total & 16 & 23 & 60 & 37 & 3 & 8 & 8 & 4 & 13 & 9 & 181 & 100 \\
\hline \multicolumn{13}{|c|}{ Escola particular } \\
\hline Ótimo & 2 & 2 & 12 & 4 & 1 & - & - & 1 & - & - & 22 & 18,7 \\
\hline Bom & 2 & 8 & 26 & 5 & 5 & 3 & 3 & 4 & 5 & 1 & 62 & 52,5 \\
\hline Regular & - & 3 & 13 & 1 & - & 2 & 2 & 2 & 5 & 1 & 29 & 24,6 \\
\hline Ruim & - & 1 & 3 & 1 & - & - & - & - & - & - & 5 & 4,2 \\
\hline Péssimo & - & - & - & - & - & - & - & - & - & - & - & 0,0 \\
\hline Total & 4 & 14 & 54 & 11 & 6 & 5 & 5 & 7 & 10 & 2 & 118 & 100 \\
\hline \multicolumn{13}{|c|}{$\begin{array}{l}\text { Escola pública/ } \\
\text { particular }\end{array}$} \\
\hline Ótimo & - & - & 1 & - & - & 1 & - & - & - & - & 2 & 6,3 \\
\hline Bom & 3 & 2 & 10 & - & 1 & - & - & 1 & 2 & 1 & 20 & 62,5 \\
\hline Regular & - & 2 & 2 & - & 1 & 1 & - & - & - & 1 & 7 & 21,9 \\
\hline Ruim & - & - & 1 & - & - & - & - & - & - & - & 1 & 3,1 \\
\hline Péssimo & - & 1 & 1 & - & - & - & - & - & - & - & 2 & 6,2 \\
\hline Total & 3 & 5 & 15 & - & 2 & 2 & - & 1 & 2 & 2 & 32 & 100 \\
\hline
\end{tabular}

fonte: Rev. Trabalho, Educação e Saúde 
O hiato de três anos entre o término do ensino médio e a entrada em um curso técnico pós-médio instiga-nos a pensar sobre o que teria acontecido a esses alunos naquele período, logo quando estavam a um passo do ensino superior. Teriam eles procurado ingressar no ensino superior? Prestaram vestibular? Foram aprovados? Em que tipo de instituição - pública ou privada — obtiveram aprovação? Chegaram a freqüentar algum curso superior? Pode-se relacionar a realização de um curso técnico pós-médio com a ocorrência de tentativas frustradas de ingresso e permanência no ensino superior?

A grande maioria dos alunos dos cursos técnicos pós-médios, 74\%, correspondentes a 246 alunos, realizou os exames vestibulares, mas apenas $59 \%$ obtiveram aprovação (Tabela 7). Entre os 144 alunos dos cursos técnicos pós-médios que foram aprovados nos vestibulares, pouco mais da metade, cerca de 55,6\%, obtiveram aprovação para as Instituições de Ensino Superior (IES) públicas.

Entre os 144 alunos aprovados no vestibular, 43,7\% eram egressos de escolas privadas, $42,4 \%$ de escolas públicas e os $13,8 \%$ restantes haviam realizado parte de seus cursos de 20 grau em escola pública e parte em escola particular.

Boa parte dos alunos procedentes de escolas privadas, cerca de 71,4\%, foi aprovada nas IES públicas. Já a maioria dos alunos que concluíram seus cursos de 2 o grau em uma escola pública — 60,6\% — obteve aprovação nos vestibulares das IES privadas.

Conforme se pôde constatar, os resultados dos alunos que realizaram o então curso de 2 o grau em uma escola pública comparados aos dos que o fizeram em uma escola privada revelam que a obtenção desse grau em uma instituição privada ainda constitui um fator significativo no percurso dos alunos que obtiveram aprovação nos vestibulares das IES públicas.

A realização de um curso pré-vestibular parece constituir também um fator decisivo para a aprovação nos vestibulares das IES públicas. Entre os 80

Tabela 7

Distribuição do número de alunos dos cursos técnicos pós-médios segundo a origem escolar e o tipo de instituição de ensino superior no qual foram aprovados

\begin{tabular}{lccccc}
\hline $\begin{array}{l}\text { Origem escolar } \\
\text { dos alunos }\end{array}$ & \multicolumn{2}{c}{ IES Públicas } & \multicolumn{2}{c}{ IES Privadas } & Total \\
& $\begin{array}{l}\text { com curso } \\
\text { pré-vestibular }\end{array}$ & $\begin{array}{c}\text { sem curso } \\
\text { pré-vestibular }\end{array}$ & $\begin{array}{c}\text { com curso } \\
\text { pré-vestibular }\end{array}$ & $\begin{array}{c}\text { sem curso } \\
\text { pré-vestibular }\end{array}$ & \\
\hline Escola pública e privada & 7 & 4 & 5 & 4 & 20 \\
Escola pública & 15 & 9 & 16 & 21 & 61 \\
Escola privada & 22 & 23 & 8 & 10 & 63 \\
Total & 44 & 36 & 29 & 35 & 144 \\
\hline
\end{tabular}


alunos nelas aprovados, 44 - cerca de 60,6\% - freqüentaram um curso prévestibular. Já em relação aos aprovados nas IES privadas, a taxa foi de apenas $38 \%$ (Tabela 8). Assim, o curso pré-vestibular somente deixou de ser condição essencial para os aprovados nas instituições de ensino superior privadas.

A diferença mais marcante entre os alunos dos cursos técnicos pós-médios, segundo o curso de 2 o grau realizado, é que enquanto os alunos provenientes das escolas privadas obtinham melhores resultados nos vestibulares das IES públicas, os provenientes das escolas públicas só conseguiam ingressar nas IES privadas.

E os alunos reprovados? Dos alunos reprovados no vestibular para as IES, $81,9 \%$ procederam exclusivamente da escola pública. Quase metade dos alunos da escola pública, 42,4\%, mesmo tendo realizado um curso de preparação para o exame, não foi aprovada.

$\mathrm{O}$ "bom" índice de aprovação obtido pelos alunos nas IES privadas deve-se ao grande número de vagas oferecidas para os diversos cursos nessas instituições - em que, portanto, é baixa a relação candidato-vaga - o que facilita o ingresso nos cursos superiores. Além disso, algumas IES chegam a promover vários vestibulares durante o início de cada semestre letivo visando ao preenchimento de vagas, o que certamente amplia as chances de aprovação.

Mas, o que aconteceu com os alunos aprovados no vestibular? Qual o seu percurso escolar? Puderam realizar o curso superior em que ingressaram? Há diferenças de percurso entre os aprovados nas IES públicas e os aprovados nas IES privadas?

Entre os alunos aprovados no vestibular, 15,3\% concluíram o curso superior, $28,5 \%$ abandonaram-no, 25\% trancaram a matrícula e 31,9\% seguiram cursando a faculdade e realizando o curso técnico pós-médio (Tabela 9).

Nesta última situação, a maioria dos alunos estava no CEFET. Esses alunos avaliavam de forma positiva o fato de realizarem também um curso téc-

Distribuição do número de alunos dos cursos técnicos pós-médios reprovados no vestibular segundo a origem escolar, a realização de cursinho e a avaliação do curso de 20 grau

\begin{tabular}{lccccc}
\hline & \multicolumn{5}{c}{ Avaliação do curso de 2 grau } \\
Origem escolar & Ótimo & Bom & Regular & Ruim & Péssimo \\
\hline Escola pública com curso pré-vestibular & - & 10 & 13 & 4 & 1 \\
Escola pública sem curso pré-vestibular & 3 & 12 & 13 & 9 & 1 \\
Escola privada com curso pré-vestibular & 1 & 8 & 7 & - & - \\
Escola privada sem curso pré-vestibular & 5 & 6 & 3 & 1 & - \\
Total & 9 & 36 & 36 & 14 & 2 \\
\hline
\end{tabular}


Distribuição do número de alunos dos cursos técnicos pós-médios segundo a instituição, a especialidade e a situação escolar no ensino superior

\begin{tabular}{|c|c|c|c|c|c|c|c|c|c|c|c|c|}
\hline \multirow{2}{*}{$\begin{array}{l}\text { Situação atual } \\
\text { dos aprovados }\end{array}$} & \multicolumn{3}{|c|}{ CEFET } & \multirow{2}{*}{$\begin{array}{l}\text { ETFQ } \\
\text { Química }\end{array}$} & \multicolumn{6}{|c|}{ SENAI } & \multirow{2}{*}{ Total } & \multirow[t]{2}{*}{$\%$} \\
\hline & $\begin{array}{l}\text { Sanea- } \\
\text { mento }\end{array}$ & $\begin{array}{l}\text { Seg. do } \\
\text { Trabalho }\end{array}$ & $\begin{array}{l}\text { Teleco- } \\
\text { munic. }\end{array}$ & & $\begin{array}{l}\text { Instru- } \\
\text { ment. }\end{array}$ & $\begin{array}{l}\text { Instal. } \\
\text { e Edific. }\end{array}$ & Solda & $\begin{array}{l}\text { Progr. } \\
\text { Visual }\end{array}$ & $\begin{array}{l}\text { Eletro- } \\
\text { técnica }\end{array}$ & $\begin{array}{l}\text { Mecâ- } \\
\text { nica }\end{array}$ & & \\
\hline Concluiu o curso & 6 & 6 & 4 & - & - & - & - & 4 & 1 & 1 & 22 & 15,3 \\
\hline Deixou o curso & 2 & 3 & 18 & 2 & 2 & 4 & 3 & 3 & 3 & 1 & 41 & 28,5 \\
\hline Trancou o curso & 6 & 4 & 14 & 3 & 2 & - & 3 & 1 & 3 & - & 35 & 25,0 \\
\hline $\begin{array}{l}\text { Faz Curso Técnico } \\
\text { e Faculdade }\end{array}$ & 4 & 4 & 31 & 6 & - & - & - & - & - & - & 46 & 31,2 \\
\hline Total & 18 & 17 & 67 & 11 & 4 & 4 & 6 & 8 & 7 & 2 & 144 & 100 \\
\hline
\end{tabular}

nico. Consideravam que esse curso apresentava um caráter mais teórico-prático que auxiliava na formação pretendida no ensino superior. Os alunos da ETFQ que seguiam o curso superior na área de Química também valorizavam a formação do curso técnico que estavam freqüentando. Alguns chegaram a lamentar não terem encontrado nas IES laboratórios e professores tão bons como encontraram no curso técnico pós-médio.

No SENAI, há uma maior concentração de alunos que não permaneceram no ensino superior: dos 31 alunos aprovados no vestibular, 16 deixaram seus cursos e oito trancaram suas matrículas, ou seja, 77,4\% interromperam seus cursos. Quase todos os alunos, embora não pudessem custear um curso superior em uma IES privada, consideraram mais viável realizar um curso técnico, que, apesar de pago - cerca de um salário mínimo por mês - , poderia ser completado em menor tempo que o superior.

Entre os alunos aprovados para as instituições públicas, cerca de 21,2\% deixaram o curso, 18,7\% trancaram a matrícula, 52,5\% permaneciam cursando e 7,5\% concluíram. Em relação às instituições privadas, os percentuais foram $38 \%, 31,7 \%, 6,3 \%$ e $25,3 \%$, respectivamente. Portanto, o abandono e o trancamento são maiores entre os alunos aprovados nas IES privadas, assim como maiores as possibilidades de os alunos continuarem seguindo um curso superior em uma IES pública (Tabela 10).

Outra diferença entre os percursos escolares dos alunos aprovados nas IES públicas e nas IES privadas diz respeito aos motivos alegados para o abandono e o trancamento dos cursos superiores. Os alunos das IES privadas, na maioria das vezes, atribuíram o abandono essencialmente à falta de recursos financeiros. Os cursos mais caros eram da área Tecnológica, como o de Engenharia, por exemplo.

Alguns alunos que abandonaram o curso em IES públicas, no entanto, relataram como principal motivo a falta de identificação com o curso que es- 


$\begin{aligned} & \text { Distribuição do número de alunos dos cursos técnicos pós-médios aprovados no vestibular } \\
& \text { segundo o tipo de instituição e a situação em que se encontravam no ensino superior }\end{aligned}$
\begin{tabular}{lccccc}
\hline SIES & Abandonaram & Trancaram & $\begin{array}{c}\text { Seguiam } \\
\text { cursando }\end{array}$ & $\begin{array}{c}\text { Concluíram o } \\
\text { curso superior }\end{array}$ & Total \\
\hline Públicas & 17 & 15 & 42 & 6 & 80 \\
Privadas & 24 & 20 & 4 & 16 & 63 \\
Total & 41 & 35 & 46 & 22 & 144 \\
\hline
\end{tabular}

tavam realizando. Não correspondia aos seus interesses intelectuais ou às expectativas relativas ao futuro profissional. Para eles, os cursos escolhidos não possibilitavam ascensão social, referiam-se a áreas já saturadas ou de baixo prestígio.

Os alunos que trancaram a matrícula do curso superior nas instituições particulares afirmaram ter esbarrado em obstáculos diversos, principalmente relacionados a dificuldades financeiras, tais como perda de bolsas de estudo, perda de emprego e aumento exacerbado das mensalidades. Muitos alunos também alegaram que o curso não oferecia condições mínimas de preparo para o mercado de trabalho.

Já os que trancaram as matrículas nas IES públicas apresentaram como principal motivo a impossibilidade de realizar cursos em horário integral e trabalhar. O menor tempo gasto com uma formação profissional de nível técnico e a conseqüente possibilidade de continuar trabalhando levavam-nos, portanto, a dar prioridade ao término do curso técnico e a tentar, posteriormente, retornar ao curso superior.

Um dado interessante entre os alunos que já concluíram o curso superior e que freqüentavam um curso técnico pós-médio foi a maior presença de alunos oriundos das IES privadas: 16 dos 22 concluintes. Para tais alunos, a conclusão de um curso superior não possibilitara a ampliação de suas chances de ascensão social ou mesmo o ingresso no mercado de trabalho. Nesses casos, o curso técnico pós-médio significava mais uma tentativa de encontrar um emprego melhor.

Ainda segundo os alunos que concluíram o curso superior, a realização de um curso técnico pós-médio poderia complementar a formação já obtida. Os cursos técnicos realizados em áreas como saneamento, segurança do trabalho e programação visual eram considerados, mais que uma formação técnica, uma especialização que complementaria a atuação de diversos profissionais com nível superior.

A maioria dos alunos que estava realizando de forma paralela o curso superior com o curso técnico pós-médio objetivava concluir uma formação 
profissional mais rápida, que pudesse possibilitar o ingresso mais imediato no mercado de trabalho na área em que também realizavam o curso superior. O técnico pós-médio era cursado porque "o técnico tem emprego mais rápido", como apontaram alguns alunos. O ensino superior era cursado porque o mercado de trabalho valorizava mais quem tivesse formação superior. A presença mais marcante de alunos nessa situação ocorreria no curso de Telecomunicações.

Portanto, a conclusão de um curso técnico pós-médio e de um curso superior seria um diferencial positivo no momento de ingresso no concorrido mercado de trabalho. No entanto, freqüentar um curso técnico e um curso superior simultaneamente era mais viável para alunos que estavam realizando seus cursos superiores em uma IES pública. Apenas quatro dos 46 alunos nessa situação estavam matriculados em uma IES particular. Os cursos técnicos pós-médios, concebidos para atender os alunos que não iam para o ensino superior, acabavam por atrair um alunado que, mesmo realizando um curso superior, procurava ampliar suas chances no mercado de trabalho.

Enfim, pergunta-se se haveria relação entre a realização de um curso técnico pós-médio e a ocorrência de tentativas frustradas de ingresso ou de permanência no ensino superior. Analisando os percursos escolares dos alunos dos cursos técnicos pós-médios, é possível afirmar que muitos deles despenderam grandes esforços para freqüentar um curso superior: cerca de $74 \%$ tentaram o vestibular.

Dos alunos que conseguiram aprovação nas IES privadas, quase $70 \%$ não permaneceram no ensino superior: ou abandonaram ou trancaram seus cursos. As dificuldades econômicas foram o principal motivo para a interrupção.

Para os alunos reprovados no vestibular e para os aprovados que não conseguiram manter-se nas IES, o curso técnico pós-médio foi a única alternativa de formação profissional encontrada. Os alunos acreditavam que, depois de terem concluído o curso, poderiam conquistar melhores trabalhos, receber bons salários e voltar a estudar.

Quase a totalidade dos 85 alunos que não prestaram o exame de vestibular pretendia, ao final do curso técnico, fazê-lo (Tabela 11). Muitos desses alunos acreditavam que a formação obtida no curso técnico poderia ajudá-los a prosseguir nos seus estudos.

Boa parte dos alunos, cerca de $98,1 \%$, pretendia realizar um curso superior na mesma área em que estava realizando o curso técnico. $\mathrm{O}$ curso superior permitiria a aquisição de conhecimentos mais profundos e traria maior possibilidade de ascensão profissional e social.

Enfim, ingressar em um curso superior não deixava de ser a grande aspiração de todos os alunos dos cursos técnicos pós-médios. Tanto os que ainda prestariam o exame de vestibular quanto os reprovados não tinham 
perdido a esperança (Tabela 12). Também mantinham, ainda, a expectativa de realizar um curso superior os alunos que haviam trancado a matrícula em seus cursos e até os que haviam abandonado a faculdade.

A maioria dos alunos que não mais desejava realizar o curso superior alegou a idade - mais de 33 anos - como motivo principal. Havia ainda, nesse grupo de maior faixa etária, alunos que se sentiam estabilizados em suas empresas e satisfeitos em apenas concluir um curso técnico. Os percursos escolares dos alunos dos cursos técnicos pós-médios revelaram a realidade de grande parte dos alunos que conseguiu concluir o ensino médio. Vieram de um ensino médio precário, que inviabilizou a continuidade de seus estudos no ensino superior.

Como já conhecessem as dificuldades que enfrentariam para prestar vestibular e para manter-se em uma faculdade particular, os alunos postergavam o ingresso no ensino superior. Até mesmo a realização de um curso técnico, para a maioria deles, só foi possível algum tempo depois de concluído o ensino médio, após as tentativas frustradas de ingresso em alguma das IES e a busca por um emprego no mercado de trabalho.

Assim, a realização de um curso de formação profissional de nível técnico em seqüência ao ensino médio foi a possibilidade concreta encontrada.

Tabela 11

Distribuição do número de alunos dos cursos técnicos pós-médios que não tentaram o vestibular segundo a instituição, a especialidade e o intento de ingressar no ensino superior

\begin{tabular}{|c|c|c|c|c|c|c|c|c|c|c|c|c|}
\hline \multirow{2}{*}{$\begin{array}{l}\text { Pretende ingressar } \\
\text { no curso superior? }\end{array}$} & \multirow[b]{2}{*}{$\begin{array}{l}\text { Sanea- } \\
\text { mento }\end{array}$} & \multirow{2}{*}{$\begin{array}{l}\text { CEFET } \\
\text { Seg. do } \\
\text { Trabalho }\end{array}$} & \multirow[b]{2}{*}{$\begin{array}{l}\text { Teleco- } \\
\text { munic. }\end{array}$} & \multirow{2}{*}{$\begin{array}{c}\text { ETFQ } \\
\text { Química }\end{array}$} & \multirow[b]{2}{*}{$\begin{array}{l}\text { Instru- } \\
\text { ment. }\end{array}$} & \multirow[b]{2}{*}{$\begin{array}{l}\text { Instal. } \\
\text { e Edific. }\end{array}$} & \multicolumn{2}{|c|}{ SENAI } & \multirow[b]{2}{*}{$\begin{array}{l}\text { Eletro- } \\
\text { técnica }\end{array}$} & \multirow[b]{2}{*}{$\begin{array}{l}\text { Mecâ- } \\
\text { nica }\end{array}$} & \multirow[t]{2}{*}{ Total } & \multirow[t]{2}{*}{$\%$} \\
\hline & & & & & & & Solda & $\begin{array}{l}\text { Progr. } \\
\text { Visual }\end{array}$ & & & & \\
\hline Sim & 1 & 13 & 20 & 15 & 2 & 6 & 3 & 3 & 9 & 6 & 78 & 91,8 \\
\hline Não & 1 & - & 1 & 0 & 1 & - & - & - & 2 & 2 & 7 & 8,2 \\
\hline Total & 2 & 13 & 21 & 15 & 3 & 6 & 3 & 3 & 11 & 8 & 85 & 100 \\
\hline
\end{tabular}

Tabela 12

Distribuição do número de alunos dos cursos técnicos pós-médios que foram reprovados no vestibular segundo o intento de ingressar no ensino superior

\begin{tabular}{cc}
\hline Pretende ingressar no curso superior? & Número de alunos que já foram reprovados no vestibular \\
\hline Sim & 98 \\
Não & 4 \\
Total & 102 \\
\hline
\end{tabular}


Todos procuravam-nos cheios de esperança: conseguir melhor emprego, melhor salário e fazer faculdade.

\section{Considerações finais}

A função manifesta da reforma pode ser retirada dos motivos expostos pelo MEC para a separação do ensino médio da educação profissional e para a opção por uma educação profissional organizada por níveis: básico, técnico e tecnológico.

A separação dos sistemas de formação - educação profissional e educação básica - apoiou-se na perspectiva de que, em tempos de mudanças tecnológicas e de globalização da economia, emergem novas demandas para a educação para o trabalho. Concorreu também para a mudança uma análise sobre a falta de identidade do ensino médio, em função do seu caráter indefinido, ora considerado terminal, ora propedêutico, aliás, recorrente na bibliografia educacional brasileira desde os anos 30 .

$\mathrm{Na}$ atual reforma definida pelo Decreto Federal 2.208/97, o MEC parte do pressuposto de que a chave do êxito dos países desenvolvidos seria especialmente em um mundo pautado pela competição, pela inovação tecnológica e pelas crescentes exigências de qualidade e produtividade - uma eficiente educação profissional, alicerçada em sólida educação básica.

Dessa forma, a prioridade educacional do país para os próximos anos será a universalização do ensino fundamental na idade própria e, progressivamente, a do ensino médio. É essencial realizar grandes esforços na instauração de um processo de contínua melhoria da qualidade da educação bási$\mathrm{ca}$, o que significa, sobretudo, preparar crianças e jovens para um mundo regido pela competição, pela inovação tecnológica e por crescentes exigências de qualidade, de produtividade e de conhecimento.

A função manifesta das atuais diretrizes para a educação é, portanto, investir na educação básica e, ao mesmo tempo, diversificar e ampliar a oferta de educação profissional, como forma de atender às metas estratégicas de desenvolvimento econômico e social do país. O grande desafio será capacitar os cidadãos para uma aprendizagem autônoma e contínua no que se refere tanto às competências essenciais, básicas e gerais, quanto às específicas e profissionais.

Para o último governo federal, a nova Lei de Diretrizes e Bases da Educação Nacional (LDB-96) e a sua regulamentação da educação profissional, o Decreto Federal n. 2.208/97, possibilitam plenamente o atendimento harmônico dessas prioridades. O Decreto concebeu uma organização curricular para o ensino técnico de forma independente do ensino médio, de modo que a formação técnica pudesse estar associada a uma educação básica 
mais sólida. A possibilidade de organização curricular através de módulos, para tornar mais flexível a formação profissional no nível técnico, representaria, assim como a certificação de competências, uma mudança importante.

Como função não-manifesta para a constituição dos dois ramos de educação - básica e profissional —, o governo, ao meu entender, pretendeu também favorecer a constituição de uma educação profissional que, ao atender os egressos do ensino médio, desviaria boa parte desses alunos das IES públicas.

Como o aumento da taxa de escolarização superior pública demandaria um grande esforço em termos de investimentos e financiamento público, o governo Fernando Henrique Cardoso apresentou como alternativa, sem aumento dos custos, a estruturação de uma educação profissional de nível técnico, ou mesmo de nível tecnológico, que se faria nas instituições públicas de educação profissional e, ainda, com abertura para realizar-se em instituições privadas. Sob o discurso da necessidade da extensão da oferta de educação básica e profissional de qualidade para todos, o MEC define-se por uma política educacional que procura conter o ingresso de parte dos egressos do ensino médio nas IES públicas.

Nesse caso, a separação no ensino médio da formação acadêmica e profissional e a modularização dos cursos de formação profissional no nível técnico constituem fatores facilitadores de atendimento a um grande contingente de egressos do ensino médio.

Paulatinamente, o governo federal se desobriga de oferecer ensino médio nas instituições de educação tecnológica federais e poderia canalizar esforços para que elas pudessem oferecer educação profissional em todos os níveis. Através das novas orientações para a educação profissional, conferese maior flexibilidade aos currículos, racionaliza-se o uso de recursos, baixam-se os custos.

A nova legislação define-se por generalizar uma alternativa já empregada para a formação profissional pós-média, com apenas uma mudança mais acentuada: cursos de educação profissional ultrapassariam o nível técnico e poderiam ser oferecidos no âmbito do ensino superior. A nova forma de desviar uma parcela dos candidatos aos exames vestibulares das IES públicas foi reorientar o sistema de educação profissional de modo a possibilitar diferentes níveis de atendimento absolutamente independentes do sistema de educação básica.

A experiência dos alunos revela que a proclamada experiência exitosa dos cursos técnicos pós-médios foi justamente a oferta de formação profissional de nível técnico para os concluintes do ensino médio, o que representou uma alternativa de formação profissional que, de certa forma, amenizou e controlou as demandas dos alunos por um ensino superior público e gratuito. 
Em inúmeros relatos, os alunos dos cursos técnicos pós-médios afirmaram que cursos bem estruturados, com sólida formação téorico-prática, que oferecessem boas possibilidades de estágios e propiciassem um "emprego garantido" eram iniciativas desejáveis. De fato, bons cursos técnicos podem ser formas de enfrentamento das desigualdades utilizadas pelos jovens que as conhecem após a conclusão do ensino médio. No entanto, é inegável vislumbrar que, para uns, o destino será a formação profissional de nível técnico e, para outros, o ensino superior.

É preciso levar em conta que muitos alunos egressos do ensino médio podem se beneficiar da realização de cursos técnicos. Podem, via educação profissional de nível técnico, inserir-se no mercado de trabalho em ocupações profissionais com perspectivas de melhor remuneração. Tal ponderação não implica, no entanto, arrefecer a luta pela democratização do ensino superior, mas visa a ampliar a abordagem da questão da profissionalização para os alunos e egressos do ensino médio.

Sem dúvida, o melhor antídoto para a desigualdade escolar é a qualidade do ensino médio público, que pode ampliar as possibilidades da maioria dos seus egressos de dar continuidade aos estudos no ensino superior em alguma das IES públicas. No entanto, ao considerar a conclusão do ensino médio como fator de melhoria também das condições de ascensão profissional, é extremamente importante repensar as necessidades dos alunos, que consideram válida a perspectiva de profissionalização que pode ser conquistada em um curso técnico.

A partir da experiência acumulada pelos cursos técnicos oferecidos após o ensino médio, pôde-se observar que, em um sistema de educação pública com raras oportunidades de oferta de cursos técnicos integrados ao ensino médio, os cursos técnicos pós-médios acabaram por ser a única e derradeira possibilidade para os alunos que, em sua maioria, não lograram ingresso no curso superior ou até mesmo para os que foram aprovados nos processos seletivos das instituições de ensino superior, mas que não puderam, por diferentes razões, prosseguir e concluir seus cursos.

Com efeito, pelo que também se observou em relação aos cursos técnicos pós-médios, os cursos técnicos de nível médio foram procurados pelos que conseguiram concluir o ensino médio, mas não reuniram condições de enfrentar a "batalha" do ingresso nas IES públicas. Em um primeiro plano, deve-se considerar que, para a maioria dos jovens das camadas de baixa renda, é praticamente impossível cursar em paralelo o ensino médio e o nível técnico da educação profissional.

Esses jovens, em sua trajetória de vida, muito cedo têm que contribuir para o orçamento, "arrumar trabalho" para sobreviver. Para a maioria desses alunos, o curso técnico só se tornará mais viável após o término do ensino médio, de forma que eles se mantenham na condição de estudantes trabalhadores. 
Diante desses aspectos, e sob o enfoque de um acesso diferenciado para a educação profissional e a educação superior, não cabe a afirmativa de que estamos diante de uma educação profissional aberta para os que por ela simplesmente optarão. Para a maioria, ainda não há opção. A experiência dos alunos dos cursos técnicos pós-médios permanece para nós como um registro das desigualdades que marcam a educação brasileira.

\section{Notas}

1 Doutora em Educação pela Universidade Federal do Rio de Janeiro, Professora Adjunta do Departamento de Formação de Professores da Faculdade de Educação da Baixada Fluminense/UERJ- Rio de Janeiro. <soniamen@uol.com.br>

2 Originalmente as análises sobre políticas de contenção ao ensino superior estão em Cunha (1975). Ao avaliar a implantação do ensino profissionalizante previsto pela lei 5692/ 71 no ensino de 2 o grau, o autor afirma que ela teve um duplo objetivo: como função manifesta, atender ao mercado de trabalho capaz de absorver os profissionais com uma qualificação técnica conquistada no nível médio; e, como função não-manifesta, favorecer uma política de contenção de matrículas no ensino superior.

Se o ensino médio passasse a ter conteúdo profissional, as universidades públicas estariam livres de ter de fazer grandes investimentos para o atendimento da demanda de vagas nos cursos de graduação. 


\section{Referências}

BRASIL. 1997. Decreto n. 2.208, de 17 de abril de 1997. Regulamenta o §2o dos arts. 39 e 42 da Lei 9.394, de 20 de dezembro de 1996, que estabelece as Diretrizes e Bases da Educação Nacional. Documenta/Brasília, no 427, pp. 278-281.

CASTRO, Claudio de Moura. 1993. O sistema de apoio mútuo para as escolas técnicas. (Mimeo).

_.1997. O secundário esquecido ou um desvão do ensino?. Textos para a discussão MEC/INEP(Brasília), V.1, no 2 .

CASTRO, Maria Helena G. 1998. Avaliação do sistema educacional brasileiro: tendências e perspectivas. Ensaio: avaliação e políticas públicas em Educação. 6(20):303-364.

CUNHA, Luís Antonio. 1975. Educação e desenvolvimento social no Brasil. Rio de Janeiro: Francisco Alves.

. 1977. Politica educacional no Brasil: a profissionalização do ensino médio. Rio de Janeiro: Eldorado.
_. 1995. Educação Brasileira: projetos em disputa. São Paulo: Cortez.

_. 1995. Educação, estado e democracia no Brasil. São Paulo: Cortez.

- 1998. Ensino médio profissional: da fusão à exclusão. In: Anais da 20a Reunião da ANPEd, Resumos, Associação Nacional de Pós-Graduação e Pesquisa em Educação.

CURY, Carlos Roberto Jamil et al. 1982. A profissionalização do ensino na Lei 5692/ 71. Brasília: Instituto Nacional de Estudos e Pesquisas Educacionais.

DEMO, Pedro. 1997. A nova LDB: ranços e avanços. Campinas: Papirus.

KUENZER, Acácia Z. 1985. Pedagogia da fábrica: as relações de produção e educação do trabalhador. São Paulo: Cortez. 1992. Ensino de 2o grau: o trabalho como princípio educativo. São Paulo: Cortez. 1997. Ensino médio e profissional: as politicas do estado neoliberal. São Paulo: Cortez. 